\title{
Importance of monitoring temperature in the improvement of groundwater models - an example from an open pit mine in Papua New Guinea
}

\author{
E de Sousa Pells Sullivan Meynink, Australia \\ M Fowler Pells Sullivan Meynink, Australia
}

GE Swarbrick Pells Sullivan Meynink, Australia

\begin{abstract}
Although the use of temperature data in groundwater studies is well-established, temperature measurements are somehow underutilised or neglected in mining hydrogeology. Groundwater models, when calibrated solely with head data, often lead to non-unique solutions, providing similar head distributions as long as the ratios between permeabilities and boundary flows are preserved. The use of temperature data provides an environmental tracer and a proxy for heat and water mass balance, constraining the model parameters and increasing model reliability.
\end{abstract}

A case study from an open pit mine in Papua New Guinea is presented to illustrate the value of temperature measurements. As part of the geotechnical programme, pore pressures and temperatures have been monitored since beginning of mining using vibrating wire piezometers (VWPs). The monitoring of vertical temperature profiles identified the interplay between deep geothermal upflows and low-temperature rainfall infiltration.

Parameter inversion has been undertaken to estimate rates of geothermal upflow and rainfall infiltration. northeastern portions of the area present lower temperatures close to the surface, resulting from higher rainfall infiltration.

The use of temperature measurements not only increased the confidence on the groundwater model parameters, but was also instrumental for the mapping of dual-phase (steam) zones, which is critical for the understanding of the pore pressure distributions.

\section{Introduction}

The use of temperature data in groundwater studies and is well-developed and thoroughly researched in the field of environmental tracers (Cranswick et al. 2014; Kulongoski \& Izbicki 2008; Drake et al. 2010), where it is used for analysing surface-groundwater interaction dynamics, as well as recharge estimation. Nevertheless, groundwater studies in mining environments hardly make any use of temperature data.

Standard practice of pore pressure monitoring in mines commonly makes use of VWPs, which often provide temperature readings in conjunction with pore pressures. This temperature data, however, is in the vast majority of times underutilised or neglected altogether.

The fundamental equation of groundwater flow, also known as Darcy's law, establishes the relation between groundwater fluxes, hydraulic gradients and aquifer properties, as described in Equation 1. 


$$
q=-K \cdot \nabla h
$$

where:

$q \quad=$ discharge per unit area.

$K \quad=$ hydraulic conductivity.

$h \quad=$ hydraulic head.

The complete understanding of any groundwater system requires that the three elements described in Darcy's law are known; however, in practical terms, only one or two elements are known in most groundwater studies.

In the absence of groundwater flow data, any attempt to model a groundwater system will be inherently non-unique, as the hydraulic gradients can be replicated under different parameter configurations as long as the ratios between groundwater fluxes (e.g. recharge) and permeability values remain unaltered.

The objective of this paper is to demonstrate how the use of temperature data can contribute to reducing non-uniqueness by providing indirect information about groundwater fluxes and water balance. A case study developed in Papua New Guinea is presented, where a numerical model was firstly calibrated solely against pore pressure measurements, and later calibrated using pore pressures and temperature readings in conjunction.

\section{Methodology}

In order to demonstrate the importance of temperature data in the improvement of groundwater models, a case study of an open pit mine in Papua New Guinea is presented. Pore pressure and temperature monitoring has been in place as part of the geotechnical programme since the beginning of mining. A calibrated numerical model (here called Base Case) has been developed to provide predictive estimates of pore pressure and temperature for the site.

The temperature data has been interpreted and utilised in the conceptualisation stage for the definition of recharge zones and relations between recharge and geothermal upflow.

This numerical model is used to demonstrate the problem of non-uniqueness and to illustrate how temperature data can be used to minimise it. The model performance is assessed in terms of residuals, which are the differences between simulated and observed values. Average residual and root mean squared residual (RMS) values are the performance indicator presented in this paper.

Firstly, the numerical model assessed only in terms of pore pressure residuals. Sensitivity runs were prepared where all the model parameters were multiplied by the same factor. Residuals and RMS values of these runs were compared to the base case model.

In the second part, the numerical model is assessed using both pore pressure and temperature residuals. The same sensitivity runs were utilised, now analysing residuals and RMS values for pressure and temperature.

\section{$3 \quad$ Numerical model}

\subsection{Conceptualisation}

The study site lies on a collapsed caldera of an extinct volcano and is characterised by intense geothermal activity, elevated rainfall rates and proximity to the sea, conditions which when combined produce elevated pore pressures within the pit slopes. 
In terms of hydrogeological units, three major zones can be defined:

- An upper low permeability unit comprised of argillic oretypes.

- An intermediate unit of high permeability, occurring mostly in the central portions of the catchment.

- A lower unit of moderate to low permeability.

Groundwater flow is driven by rainfall recharge and geothermal flow. Low-temperature water from rainfall recharge and high-temperature geothermal water flows through the different hydrogeological units towards the ocean, which is the main natural discharge zone in the area.

\subsection{Numerical implementation}

A numerical model was developed for the site with the objective of providing predictive estimates of pore pressures and temperatures along the pit walls. This model has been described in detail in de Sousa et al. (2013) and is briefly summarised in this section.

The numerical model was developed using FEFLOW (DHI WASY GmbH 2012) and comprised the entire collapsed caldera. The model contains approximately 2.5 million elements vertically distributed into 60 layers, with 42,000 elements per layer.

Parameter zones defined in the model were based on oretypes defined at the site and provided as block models. Parameter zones for each oretype, marine sediments, the ocean and the landslide have been set, in a total of 10 zones. Figure 1 illustrates the model domain and distribution of the parameter zones.

The model was calibrated against temperature and pore pressure readings from 213 VWPs installed between 2000 and 2012. Calibration was undertaken manually and with the use of PEST (Doherty 2007), which optimises the model residuals by varying the model parameters within realistic ranges.

This calibrated model is the base case on which the non-uniqueness problem and sensitivities presented in this paper are based.
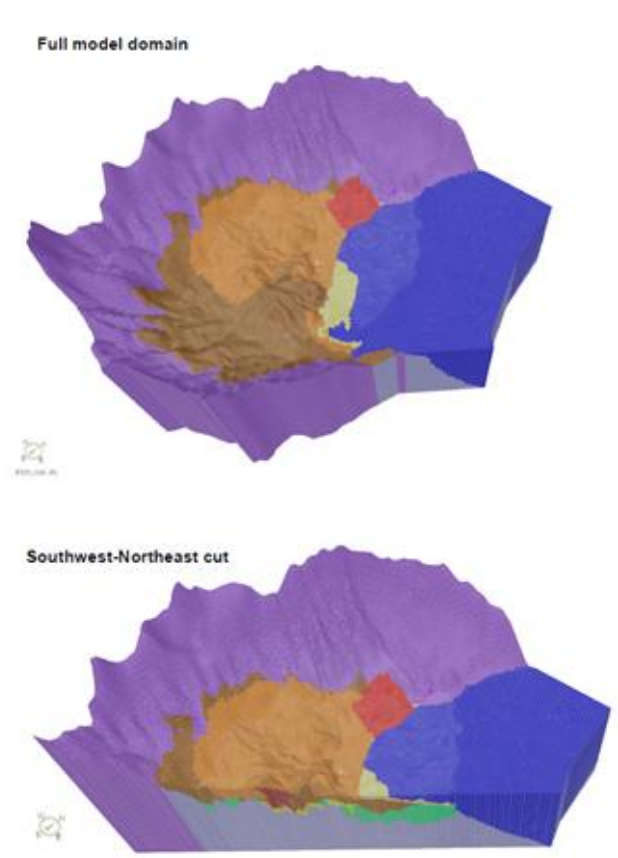
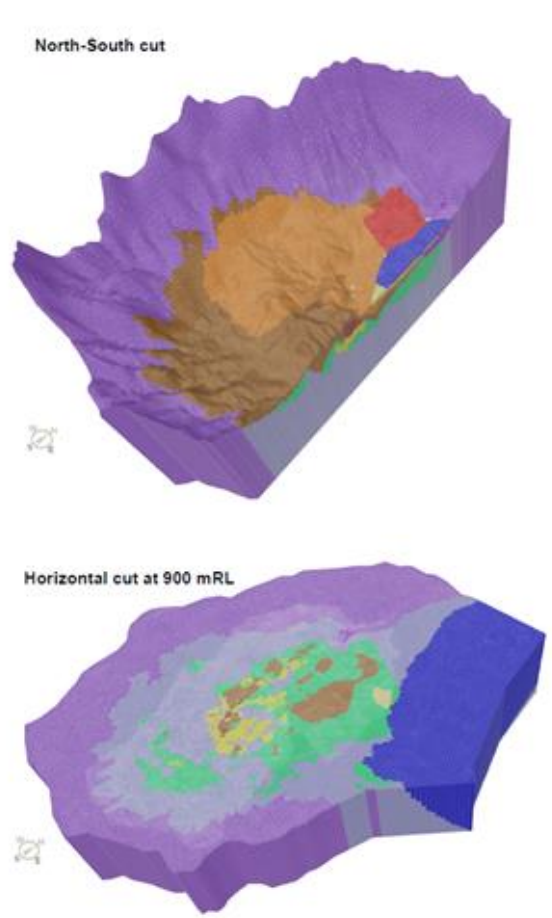

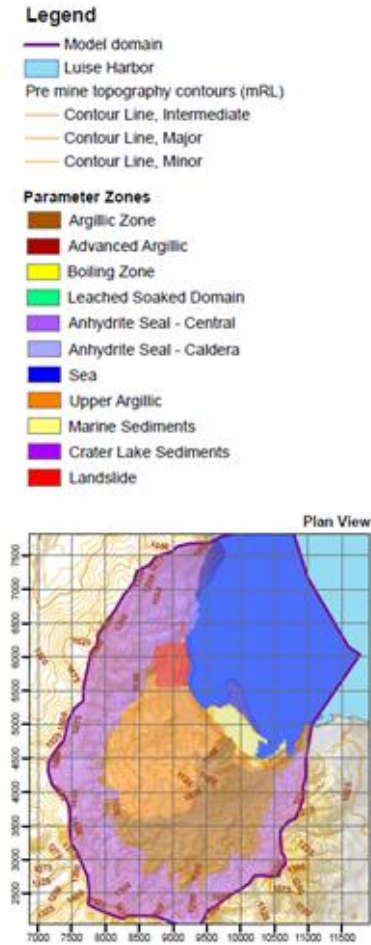

Figure 1 Numerical model domain and parameter zones 


\section{$4 \quad$ Using temperature to improve conceptualisation}

Groundwater flow in the catchment is driven by two major sources, namely the rainfall recharge and deep geothermal upflow. The temperature profile on the site is controlled essentially by the balance between the low-temperature rainfall recharge, and high-temperature geothermal upflows, as illustrated in Figure 2.
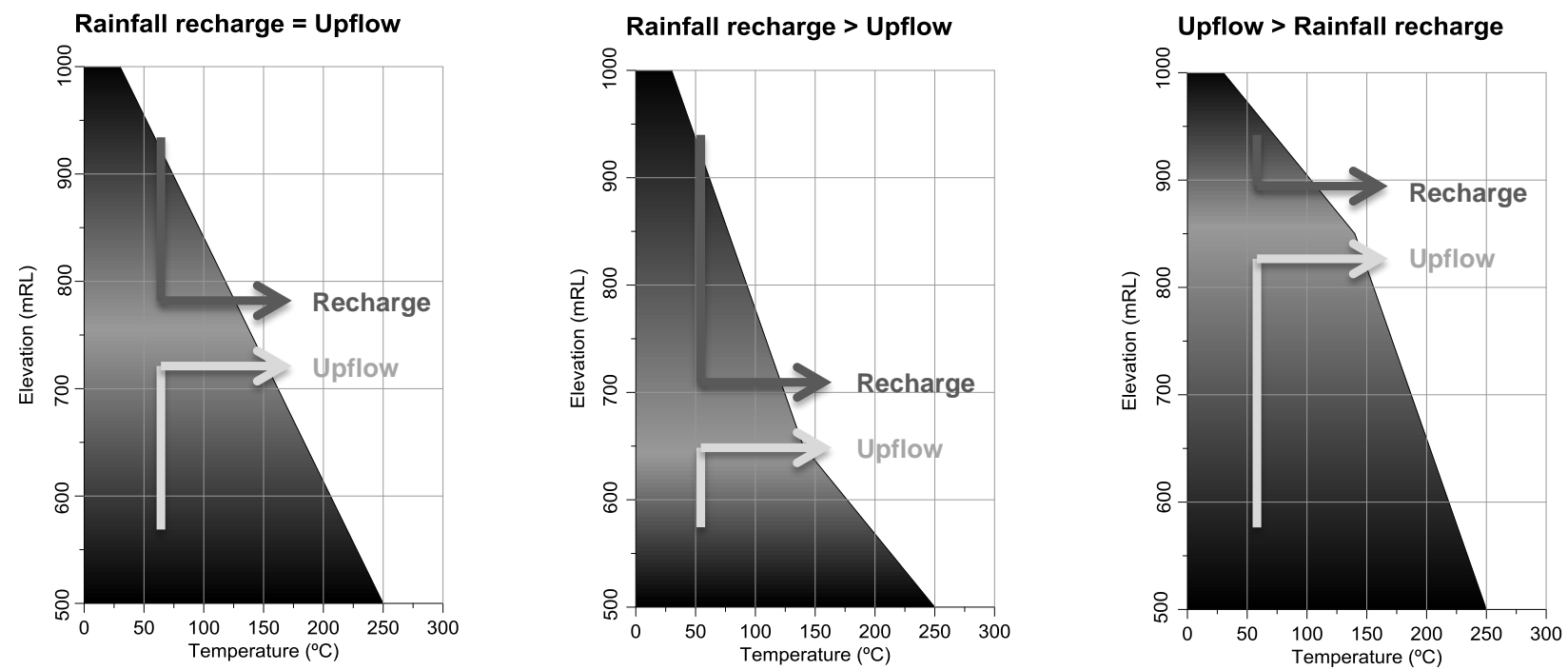

Figure 2 Schematic representation of the conceptual model for temperature distribution as a function of rainfall recharge and geothermal upflow

In areas dominated by rainfall recharge, this cold water front reaches deeper levels lowering the temperature profile, while in areas dominated by the geothermal upflow will promote high-temperature water raising to shallower levels, and consequently increasing the temperature profile.

Figure 3 display interpreted pre-mine temperatures, based on the temperature readings within the upper argillic zone. From a conceptual perspective, the distribution of temperatures indicates two zones of particular interest.

A high temperature $\left(>100^{\circ} \mathrm{C}\right)$ cluster can be found between 4,500 and $5,400 \mathrm{mN}$, where a large surface expression of geothermal features is also found. This, in conjunction with structural data from the site, suggests the presence of a high upflow zone in the area.

Further north of the high upflow zone, another cluster with low temperature is found in the immediate vicinity of high temperature readings. Following the conceptual model of temperature distributions, this would imply in recharge rates higher than the geothermal upflows, indicating that the high upflow zone is likely structurally constrained. Furthermore, a landslide occurred in the area has likely contributed to an increase in rainfall recharge, and providing low temperature water to deeper levels.

Initially these two zones have not been differentiated in the conceptual model, as the pore pressure readings in the area are relatively similar. In this situation, the temperature data not only was instrumental for the definition of this zone, but also contributed to the definition of the different groundwater sources and ratios between recharge and geothermal upflow.

Lower temperatures found in the southern portions of the catchment are also likely related to their larger distance from the upflow zone. 


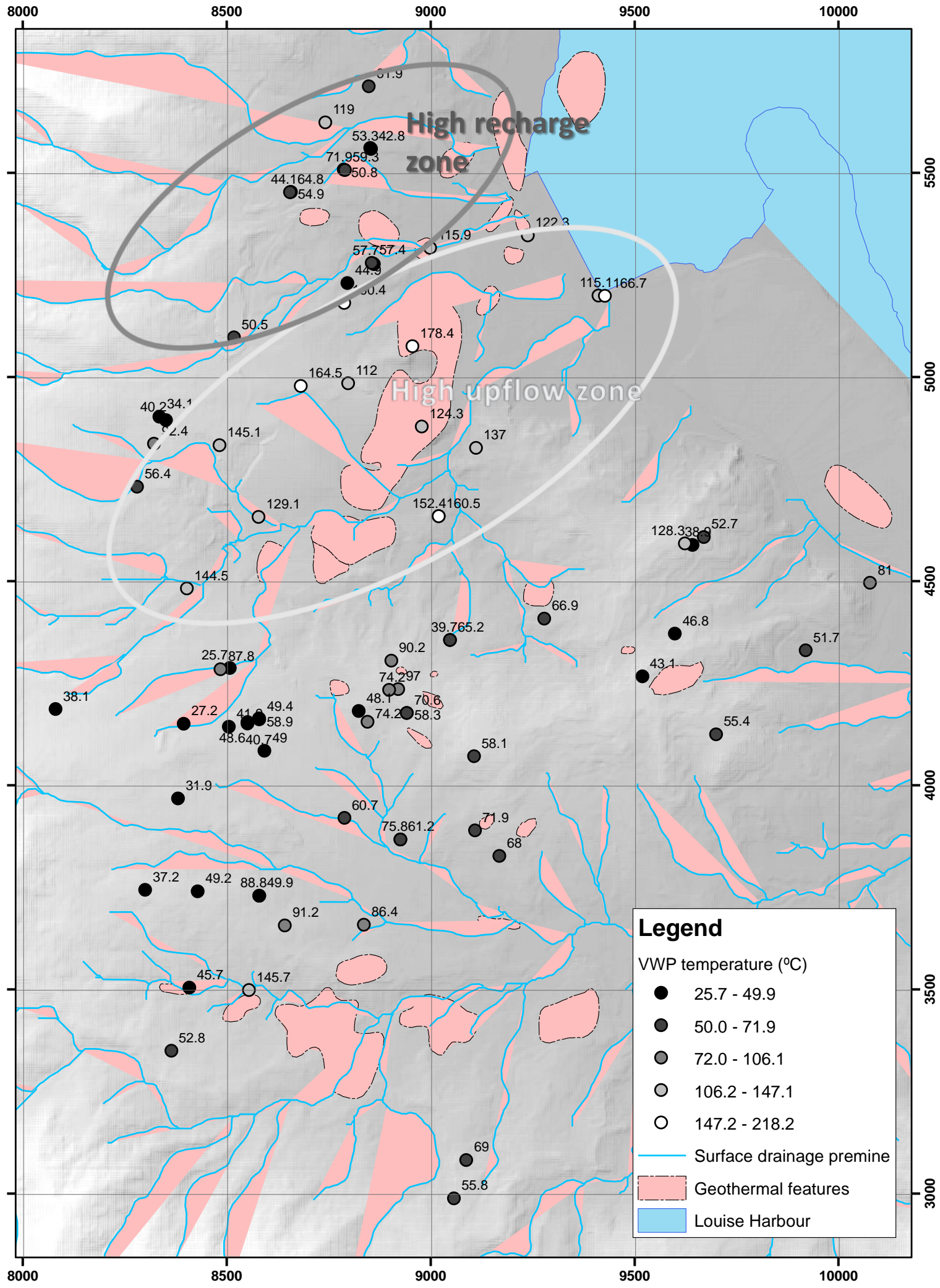

Figure 3 Pre-mine temperature distribution in the Argillic Zones, interpreted from VWP data 


\section{$5 \quad$ Using temperature to reduce non-uniqueness}

Sensitivity runs based on the base case were undertaken to illustrate the non-uniqueness of the model solution when only pore pressure (or hydraulic heads) readings are used in the calibration processes. These runs consisted in using different multipliers for the calibrated parameter values. The multipliers were 0.1, $0.5,5$ and 10 , covering two orders of magnitude. Calibrated versus observed head plots for the base case and sensitivity runs are presented in Figure 4.

The results indicate that virtually no changes in simulated heads will occur regardless the multiplier values, as long as the ratios of values between the different parameter zones are preserved. From this perspective, any of the sensitivity runs or any model with the same parameter value ratios could achieve the same calibration performance.

The non-uniqueness problem is, however, solved when the temperature data is included in the calibration, as shown in Figures 5 and 6 . The sensitivity runs now were assessed using both pore pressure and temperature readings.

The calibration results show that while the pore pressure calibration does not change for the different sensitivity runs, the temperature calibration does. Figure 6 illustrates that the temperature RMS worsen in the sensitivity runs as they deviate from the base case values, suggesting that the base case calibration is the non-unique solution of the system, since is the one who has the best combined RMS (smallest residual average) for both temperatures and heads.

While the multipliers do not affect the hydraulic gradients, they do affect the heat inflow at the base of the model. Multipliers higher than one will provide larger geothermal upflows, increasing the heat inflows and overpredicting the temperatures, as observed in the average residual plot (Figure 6). For multipliers smaller than one, the reduced heat inflow will result in temperature underprediction.

Therefore, the determination of heat inflows through the temperature data constraints the geothermal upflows of the system, and eliminate model non-uniqueness. 

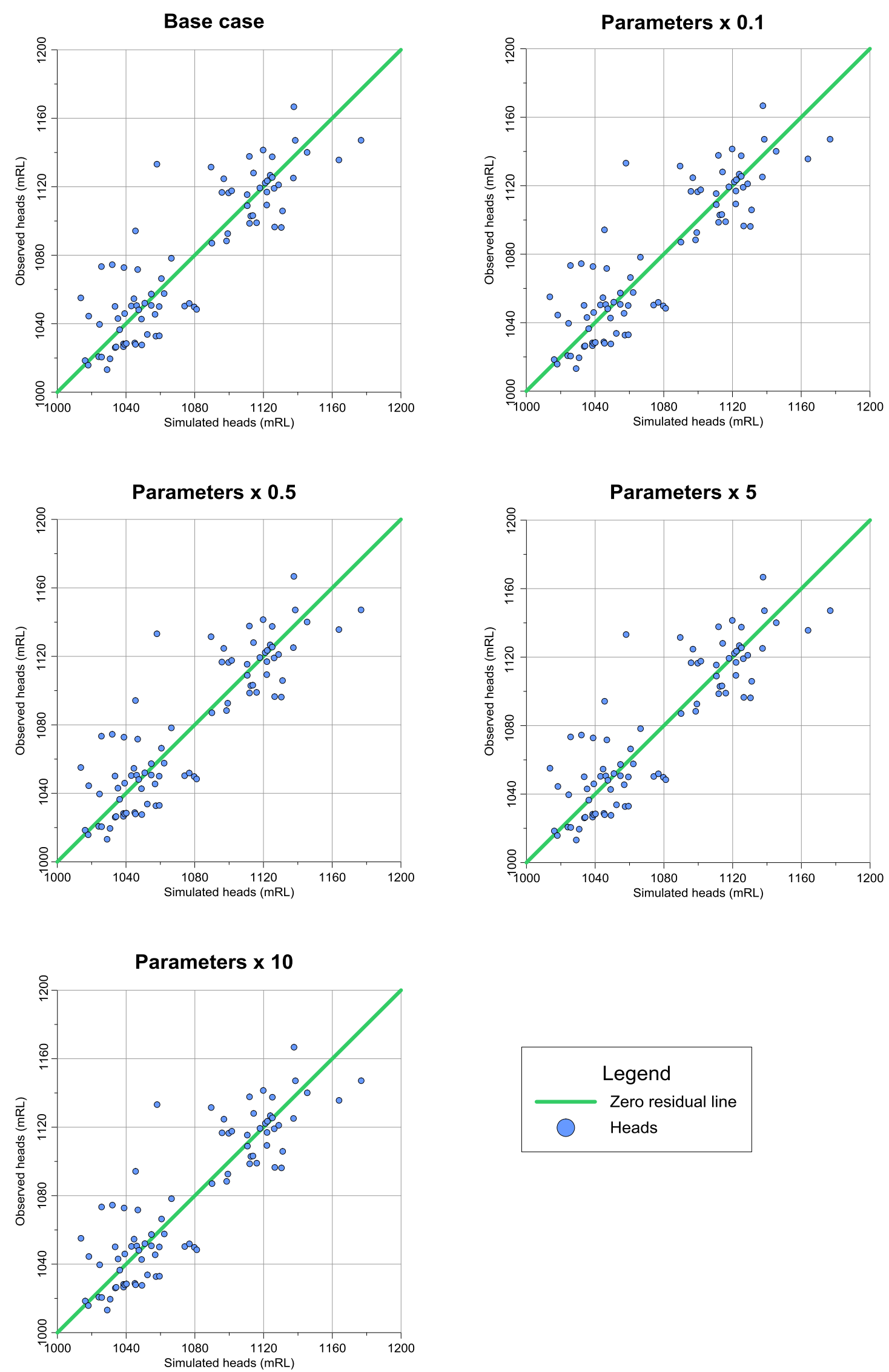

Figure 4 Calibrated versus observed heads for the base case and sensitivity runs $(\times 0.1$, $0.5,5$ and 10) 

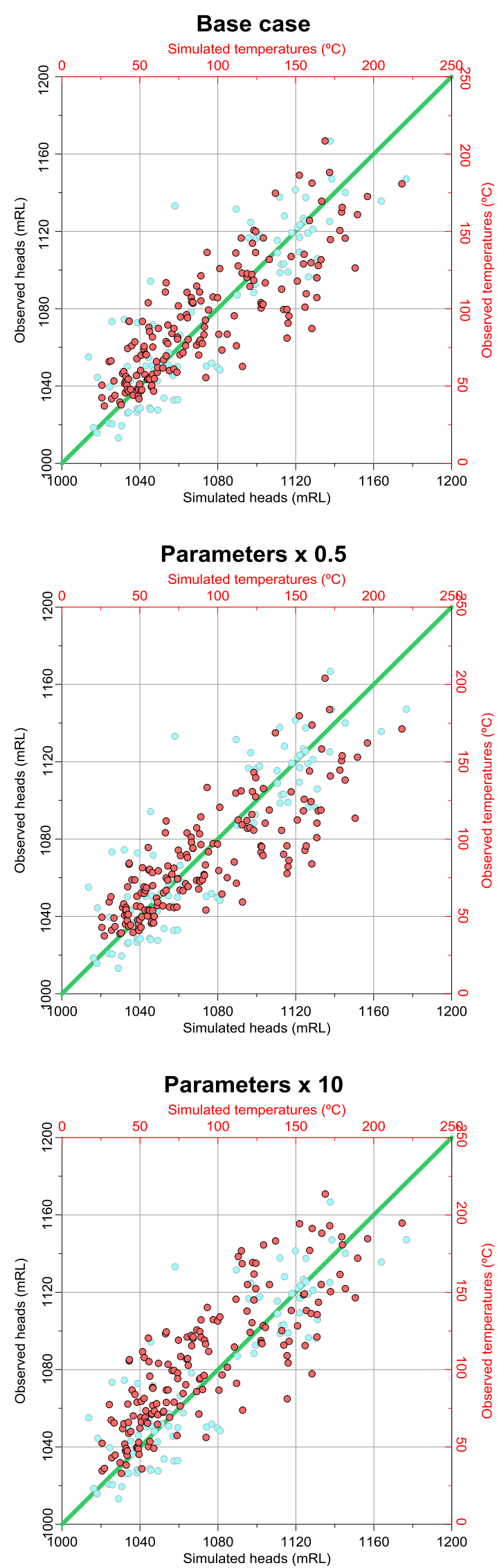

Figure 5 Calibrated versus observed heads and temperatures for the base case and sensitivity runs $(\times 0.1,0.5,5$ and 10$)$
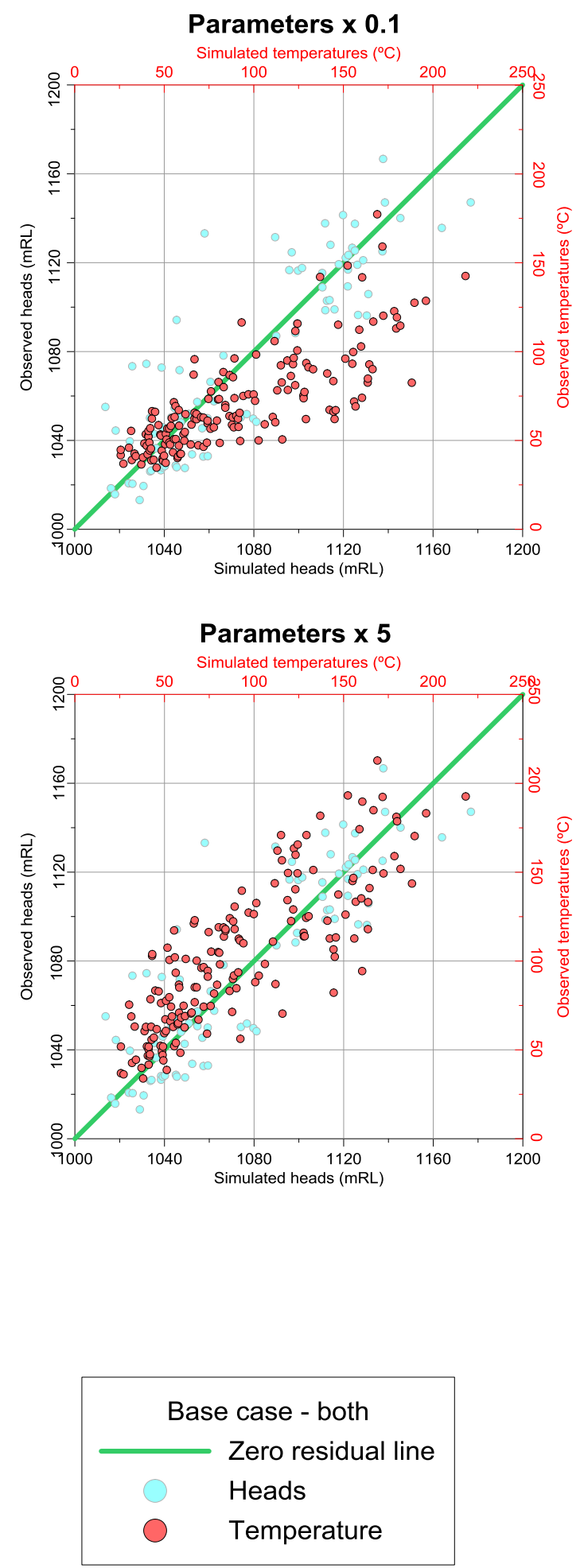

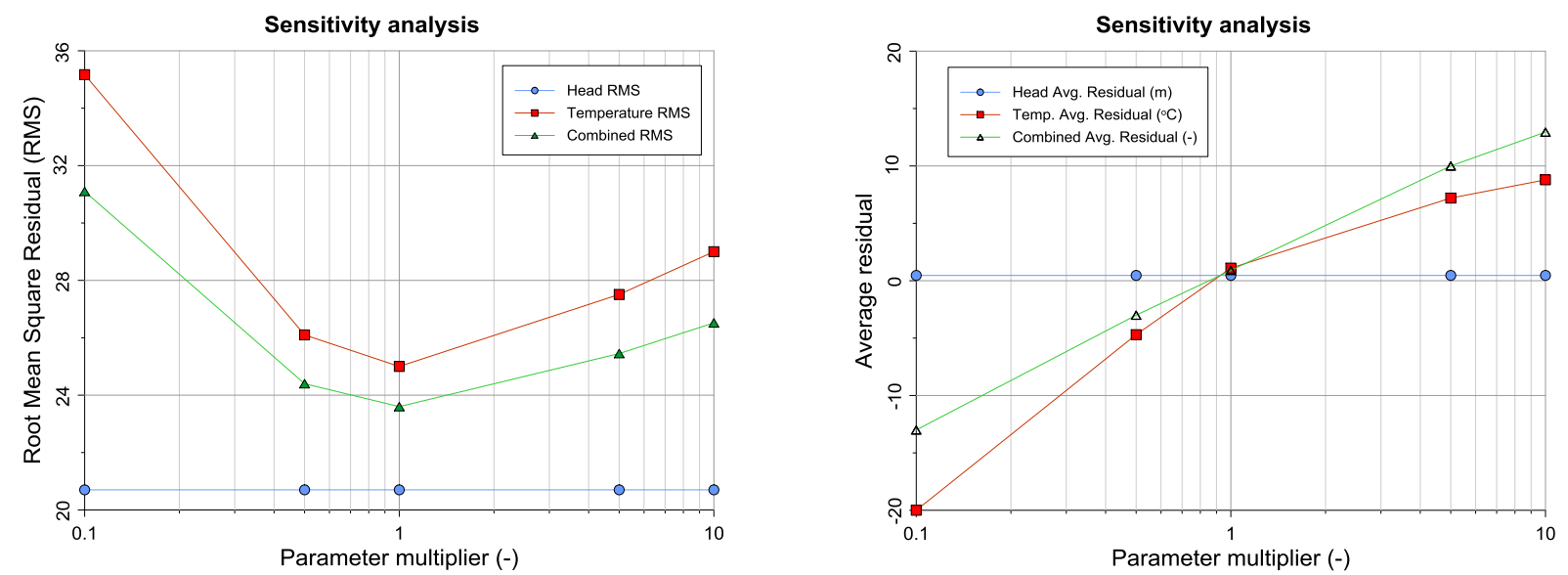

Figure 6 Sensitivity analyses for head and temperature calibration statistics

\section{Conclusion}

In the case study presented in this paper, temperature data not only contributed to improving the conceptual understanding of the site by identifying different recharge and upflow zones, but also dramatically reduced the non-uniqueness of the numerical solution. While a large number of parameter multipliers could equally represent the pore pressure calibration, only one optimal solution was capable to represent the best match of simulated and observed pressures and temperatures.

Temperature distribution and heat transport will not be solely controlled by the hydrogeological parameters, especially in systems where the heat flow is not dominated by advection and/or convection processes. Nevertheless, the range of heat transport parameter values for typical geology materials is very small (1-2 orders of magnitude) compared to hydraulic conductivities that can range over more than eight orders of magnitude. As a consequence, the use of temperature can still help with the calibration of flow models even if the heat properties of the materials are not well known.

Using a full 3D heat transport simulation in a groundwater model is not ideal when the simulation of temperatures is not in the modelling objectives, as it adds a considerable burden in terms of running times and computing resources. Nevertheless, the temperatures not only can be used to improve conceptual model, but also in analytical solutions for providing recharge estimates and groundwater-surface water fluxes, as demonstrated by Keery et al. (2007).

\section{Acknowledgement}

The authors would like to thanks Newcrest Mining Limited (NML) for allowing the publication of this work.

\section{References}

Cranswick, RH, Cook, PG \& Lamontagne, S 2014, 'Hyporheic zone exchange fluxes and residence times inferred from riverbed temperature and radon data', Journal of Hydrology, vol. 519, pp. 1870-1881.

de Sousa, E, Fowler, M \& Swarbrick, GE 2013, 'Three-dimensional pore pressure prediction in dual phase conditions for slope stability assessment', in P Dight (ed.), Proceedings of the 2013 International Symposium on Slope Stability in Open Pit Mining and Civil Engineering (Slope Stability 2013), Australian Centre for Geomechanics, Perth, pp. 1103-1110.

DHI WASY GmbH 2012, FEFLOW software, http://www.mikepoweredbydhi.com/products/feflow

Doherty, J 2007, User's manual for PEST version 11, Watermark Numerical Computing, Brisbane, Queensland.

Drake, J, Bradford, A \& Joy, D 2010, 'Application of HEC-RAS 4.0 temperature model to estimate groundwater contributions to Swan Creek, Ontario, Canada', Journal of Hydrology, vol. 389, no. 3-4, pp. 390-398.

Keery, J, Binley, A, Crook, N \& Smith, JWN 2007, 'Temporal and spatial variability of groundwater-surface water fluxes: Development and application of an analytical method using temperature time series', Journal of Hydrology, vol. 336, no. 1-2, pp. 1-16.

Kulongoski, J \& Izbicki, J 2008, 'Simulation of fluid, heat transport to estimate desert stream infiltration', Ground Water, vol. 46, no. 3, pp. 462-474. 
